\title{
Frequency of Small Intestinal Bacterial Overgrowth in Patients with Irritable Bowel Syndrome and Chronic Non-Specific Diarrhea
}

\author{
Uday C. Ghoshal, M.D., D.M.*, Sunil Kumar, M.Sc., Mansi Mehrotra, M.Sc., Lakshmi CP, M.D., D.M., and Asha Misra, M.Sc.,
} Ph.D.

Department of Gastroenterology, Sanjay Gandhi Post Graduate, Institute of Medical Sciences, Lucknow, India

\section{Introduction}

Small intestinal bacterial overgrowth (SIBO) occurs in varying frequency in irritable bowel syndrome (IBS). We studied the frequency of SIBO in IBS and chronic non-specific diarrhea (CNSD).

\section{Methods}

129 patients with IBS (Manning's criteria), 73 with CNSD ( $\geq 4$ weeks diarrhea with two of these tests normal [urine D-xylose, fecal fat and duodenal biopsy]) and 51 healthy controls $(\mathrm{HC})$ were evaluated for SIBO using glucose hydrogen breath test (GHBT). Diarrhea-predominant IBS (D-IBS) was grouped into CNSD. Rise in breath hydrogen 12 ppm above basal following 100 g glucose was diagnostic of SIBO.

\section{Results}

Of 129 patients with IBS, 7 were constipation (C-IBS), and 122 were of indeterminate type (I-IBS). Patients with IBS were younger than HC and CNSD (IBS vs. HC: $36.6 \mathrm{yr} \pm 11.4$ vs. $44.1 \mathrm{yr} \pm 13.6, \mathrm{p}=0.001$; IBS vs. CNSD: $36.6 \mathrm{yr} \pm 11.4$ vs. 42 $\mathrm{yr} \pm 14.5, \mathrm{p}=0.003$ ). Patients with CNSD were comparable to $\mathrm{HC}$ in age (42 yr $\pm 14.5 \mathrm{vs} .44 .1 \mathrm{yr} \pm 13.6, \mathrm{p}=\mathrm{ns})$. Patients with IBS were more often male than HC [108/129 (83.7\%) vs. 34/51 (66.7\%) $p=0.02]$; gender of CNSD and HC was comparable [male 39/73 (53.4\%) vs. 34/51 (66.7\%) $p=n s]$. SIBO was commoner in CNSD than HC [16 (21.9\%) vs. $1(2 \%), p=$ 0.003], but was comparable in IBS and HC [11 (8.5\%) vs. $1(2 \%), p=0.18]$. Patients with CNSD more often had SIBO than IBS [16 (21.9\%) vs. $11(8.5 \%), p=0.007]$.

\section{Conclusions}

SIBO was more common in CNSD including D-IBS than other types of IBS and HC.

(J Neurogastroenterol Motil 2010;16:40-46)

Key Words

Breath test, Chronic diarrhea, Malabsorption syndrome, Irritable bowel syndrome

Received: October 16th, 2009 Accepted: December 28th, 2009

(c) This is an Open Access article distributed under the terms of the Creative Commons Attribution Non-Commercial License (http://creativecommons. org/licenses/by-nc/3.0) which permits unrestricted non-commercial use, distribution, and reproduction in any medium, provided the original work is properly cited.

*Correspondence: Uday C. Ghoshal, M.D., DNB, DM, FACG

Department of Gastroenterology, Sanjay Gandhi Post Graduate Institute of Medical Sciences, Raebareli Road, Lucknow 226014, India

Tel: +91-522-266-8700 or 266-8800 (ext. 4405/4406), Fax: +91-522-266-8017 or 266-8078, E-mail: udayghoshal@gmail.com

Financial support: Mr. Sunil Kumar thanks Indian Council of Medical Research, New Delhi, towards financial support via the grant no. 3/1/2

(3)/GAS/2009-NCD-II for Senior research fellowship. Authors thank Department of Science and Technology towards support to Gastrointestinal pathophysiology and motility laboratory of the Department of Gastroenterology by an extramural research

Conflicts of interest: None. grants no. SR/SO/HS-15/2007 to UCG. 


\section{Introduction}

Irritable bowel syndrome (IBS) is a functional disorder characterized by chronic or recurrent abdominal pain, abnormal bowel habits, bloating, passage of mucus, and feeling of incomplete evacuation. ${ }^{1}$ IBS is common all over the world including Asia. ${ }^{2}$ The pathophysiology of IBS is poorly understood. ${ }^{3}$ The current hypothesis is based on the biopsychosocial concept, ${ }^{4}$ altered gastrointestinal motility, ${ }^{5}$ disturbance of visceral hypersensitivity ${ }^{6}$ and infection. ${ }^{7}$ Moreover, gut microbiota and certain intestinal pathogens are likely to contribute to pathogenesis of IBS. ${ }^{8,9}$ Small intestinal bacterial overgrowth (SIBO) is a condition characterized by abnormally high bacterial count ( $\geq 10^{5}$ colony-forming units $/ \mathrm{mL}$ ) in the proximal small intestine. ${ }^{10}$ Symptoms of SIBO include abdominal pain, bloating and diarrhea, which are similar to those observed in patients with IBS. ${ }^{11,12}$ However, there is scanty data on SIBO in patients with IBS from Asia. ${ }^{8}$

Chronic diarrhea resulting from malabsorption syndrome (MAS) due to various causes is associated with SIBO frequently. ${ }^{13}$ Patients with diarrhea-predominant IBS (D-IBS) may have SIBO more often than those without diarrhea. ${ }^{14}$ In fact, there may be some pathophysiological and etiological overlap between D-IBS and mild malabsorption syndrome. This is evidenced by the fact that patients with post-infectious IBS (PI-IBS), who have organic basis more frequently, are more often diarrhea-predominant, ${ }^{15,16}$ and have abnormal small intestinal permeability. ${ }^{17}$ Also, patients with D-IBS may have $\mathrm{SIBO}^{18}$ and lactose malabsorption ${ }^{18}$ more frequently. Since IBS is diagnosed by criteria based on combination of symptoms, ${ }^{19}$ which are common in patients with mild malabsorption syndrome, ${ }^{8}$ it is possible that some of patients with the latter condition, at least with mild disease and at an early stage, may be diagnosed as IBS, particularly if tests for mucosal malabsorption are not performed in them. Such a contention is supported by the recent reports of celiac disease diagnosed in patients presenting as IBS. ${ }^{20-22}$ Hence, it is worthwhile to study whether patients with chronic non-specific diarrhea (CNSD), who do not have malabsorption documented by appropriate investigations, more often have SIBO?

There are several methods for evaluation of SIBO. Lactulose hydrogen breath test (Lactulose HBT), ${ }^{23}$ glucose hydrogen breath test (GHBT), ${ }^{24}$ and culture of jejunal aspirate ${ }^{25}$ are common tests used to diagnose SIBO. However, GHBT has been suggested to be an acceptable method to diagnose SIBO in clinical practice as it is more specific than Lactulose HBT and is non-invasive as compared with quantitative jejunal aspirate culture. ${ }^{8,26}$ Accordingly, we aimed to study the frequency of SIBO in patients with IBS and CNSD in comparison with healthy controls (HC) using GHBT.

\section{Materials and Methods}

\section{Study subjects}

In this retrospective study, 129 patients with IBS diagnosed using Manning's criteria ${ }^{27,28}, 73$ with CNSD attending the outpatient clinic of the Department of Gastroenterology of a tertiary referral center in the northern India and $51 \mathrm{HC}$ were included. The study protocol was approved by the Institutional Ethics committee. Informed consent was obtained from all the patients and HC. Patients who received antibiotics, proton pump inhibitors and promotility or antimotility drugs within 4 weeks before inclusion into the study were excluded.

\section{Diagnostic criteria}

Urine D-xylose, quantitative fecal fat and or microscopy of Sudan III-stained specimen and duodenal biopsy were performed in patients with chronic diarrhea as indicated clinically. Chronic non-specific diarrhea was defined as non-bloody diarrhea (more than 3 semi-formed to liquid stools per day) for $\geq 4$ weeks with at least two of the following tests showing normal result [urine D-xylose, fecal fat or fecal Sudan and duodenal biopsy]. Patients with any two of the above tests abnormal (urine D-xylose $<0.8 \mathrm{~g} / 5 \mathrm{~g} / 5 \mathrm{hr}$, fecal fat $>7 \mathrm{~g} /$ day or fecal Sudan $>10$ droplet per high power field (hpf), and villous atrophy in duodenal biopsy) were excluded from this study. Patients with IBS were further subclassified into diarrhea, constipation and indeterminate type as reported previously. ${ }^{29}$ Diarrhea-predominant patients with IBS were grouped into CNSD if the investigations for mucosal malabsorption, done as indicated, were normal.

\section{Investigations for mucosal malabsorption}

\section{1) Urine D-xylose}

Urine D-xylose was estimated using colorimetric method after $5 \mathrm{~g}$ D-xylose using a standard technique. ${ }^{30}$ A value $\geq 0.8 \mathrm{~g} / 5 \mathrm{~g} / 5$ hr was considered normal.

\section{2) Fecal fat}

Fecal fat was estimated either over 72-hour using standard technique (Van de Kamer's) after challenge with 75 g extra dietary fat per day for 3 days prior to and during the test or by micro- 
scopic examination of spot stool specimen stained with Sudan III stain. $^{31}$ An average value of fecal fat excretion $>7 \mathrm{~g} /$ day by the former or more than 10 droplets of fat per high power field on microscopy by the latter technique were considered abnormal.

\section{3) Duodenal histology}

Endoscopic biopsy obtained during esophagogastroduodenoscopy was subjected to histological examination after Hematoxylin and Eosin staining. Histological parameters including villous morphology were evaluated by experienced pathologists.

\section{Glucose hydrogen breath test}

Glucose hydrogen breath test was performed using a breath gas analyzer (Bedfont gastrolyzer, Bedfont Scientific Ltd., ME13QX, England) after an overnight fast. The subjects were asked to avoid slowly absorbed carbohydrates (like bread and potato) and fiber the previous night as this might lead to high basal levels of hydrogen in the breath. Cigarette smoking and exercise were avoided two hours before and during the test, as hyperventilation can cause changes in breath hydrogen content. The subjects were then asked to brush their teeth and rinse their mouth with antiseptic mouth wash (chlorhexidine) and tap water before the test, to eliminate early peak in hydrogen due to action of oral bacteria on the test sugars. An average of four values was taken as the basal breath hydrogen level. Subjects were then asked to take $100 \mathrm{~g}$ glucose dissolved in $200 \mathrm{~mL}$ water. Thereafter, breath hydrogen values were estimated every 15 minutes for the next 3 hours. Persistent rise in breath hydrogen $>12 \mathrm{ppm}$ above basal (at least two readings) was considered diagnostic of
SIBO ${ }^{25}$ Patients with high basal breath hydrogen levels were retested on another day after ensuring all the above precautions.

\section{Statistical methods}

Categorical and continuous data were analyzed using Chi-square and Mann-Whitney $U$ test, respectively. The one-way ANOVA was done to analyze mean of maximum hydrogen excretion in three different groups. The time by group interaction was analyzed using repeated measures ANOVA (general linear model).

\section{Results}

Demographic, clinical and laboratory parameters of the study subjects are shown in Table 1. Patients with IBS were younger than $\mathrm{HC}$ (mean age $36.6 \pm 11.4$ yr vs. $44.1 \pm 13.6 \mathrm{yr}, \mathrm{p}=$ 0.001 ) and those with CNSD (mean age $36.6 \pm 11.4$ yr vs. $42 \pm$ $14.5 \mathrm{yr}, \mathrm{p}=0.003)$, respectively. Patients with CNSD were comparable in age with that of $\mathrm{HC}$ (mean age $42 \pm 14.5 \mathrm{yr}$ vs. $44.1 \pm 13.6 \mathrm{yr}, \mathrm{p}=\mathrm{ns})$. Patients with IBS were more often male than HC [108/129 (83.7\%) vs. 34/51 (66.7\%) p $=0.02]$. However, CNSD and $\mathrm{HC}$ were comparable with respect to gender [male 39/73 (53.4\%) vs. 34/51 (66.7\%) p $=0.28$ ]. Of 129 patients with IBS; 7 (5.4\%) and 122 (94.6\%) were constipation predominant (C-IBS), and indeterminate type (I-IBS), respectively. A total of 20 patients with D-IBS were included in CNSD. A total of 7 patients with IBS and 6 patients with CNSD were excluded from the study as two or more tests of mucosal malabsorption were abnormal in them. Two patients each with IBS

Table 1. Demographic, Clinical, and Laboratory Parameters of Patients and Controls

\begin{tabular}{|c|c|c|c|c|}
\hline Parameters & $\begin{array}{c}\text { IBS } \\
(\mathrm{n}=129)\end{array}$ & $\begin{array}{l}\text { CNSD } \\
(\mathrm{n}=73)\end{array}$ & $\begin{array}{l}\text { Healthy controls } \\
\qquad(\mathrm{n}=51)\end{array}$ & p-value \\
\hline Age $($ mean $\pm \mathrm{SD})(\mathrm{yr})$ & $36.6 \pm 11.4$ & $42 \pm 14.5$ & $44.1 \pm 13.6$ & $\mathrm{NS}^{\mathrm{a}}$ \\
\hline Sex (male, \%) & $108(83.7)$ & $39(53.4)$ & $34(66.7)$ & NS \\
\hline $\begin{array}{l}\text { Urine D-xylose (median and range) } \\
\mathrm{g} / 5 \mathrm{~g} / 5 \mathrm{hr}\end{array}$ & $\begin{array}{l}1.3(0.36-2.3) \\
(\mathrm{n}=22)\end{array}$ & $\begin{array}{l}1.0(0.2-2.4) \\
(\mathrm{n}=50)\end{array}$ & - & NS \\
\hline $\begin{array}{l}\text { Fecal fat (g/day) } \\
\text { (Van de Kamer's) }\end{array}$ & $\begin{array}{l}8.24(5.3-15.1) \\
(\mathrm{n}=10)\end{array}$ & $\begin{array}{l}4.97(2.6-25) \\
(\mathrm{n}=13)\end{array}$ & - & 0.008 \\
\hline $\begin{array}{l}\text { Fecal sudan (median and range) } \\
\text { (droplets/hpf) }\end{array}$ & $\begin{array}{l}14(6-20) \\
(\mathrm{n}=22)\end{array}$ & $\begin{array}{l}12(6-25) \\
(\mathrm{n}=26)\end{array}$ & - & NS \\
\hline Hemoglobin $($ mean $\pm \mathrm{SD})(\mathrm{g} / \mathrm{dL})$ & $\begin{array}{l}13.4 \pm 1.9 \\
(\mathrm{n}=80)\end{array}$ & $\begin{array}{l}12.3 \pm 2.0 \\
(\mathrm{n}=54)\end{array}$ & - & 0.002 \\
\hline GHBT (positive) & $11(8.5 \%)$ & $16(21.9 \%)$ & $1(2 \%)$ & 0.001 \\
\hline
\end{tabular}

${ }^{a}$ Patients with IBS were younger than CNSD and Healthy controls.

IBS, irritable bowel syndrome; CNSD, chronic non-specific diarrhea; NS, not significant; GHBT, glucose hydrogen breath test; SD, standard deviation.

The categorical data were analyzed using Chi-square test and continuous data were analyzed using Mann-Whitney $\mathrm{U}$ test and unpaired $\mathrm{t}$ test depending upon the data 
had cyst of Giardia lamblia and cyst of Entamoeba histolytica on stool microscopy. Only one patient with CNSD had cyst of Giardia lamblia.

\section{Results of investigations for mucosal malabsorption}

\section{1) Urine D-xylose}

Results of investigations for mucosal malabsorption are shown in Table 2. Urine D-xylose was done in 22/129 (17.1\%) patients with IBS and 44/73 (60.3\%) with CNSD. The urinary excretion of D-xylose was comparable in patients with IBS and CNSD (median $1.3 \mathrm{~g} / 5 \mathrm{~g} / 5 \mathrm{hr}$, range 0.36-2.3 g/5 g/5 hrvs. 1.0 $\mathrm{g} / 5 \mathrm{~g} / 5 \mathrm{hr}$, range $0.2-2.4 \mathrm{~g} / 5 \mathrm{~g} / 5 \mathrm{hr}, \mathrm{p}=\mathrm{ns})$.

\section{2) Fecal fat}

Fecal fat (by Van de Kamer's method) was done in 10/129 (7.7\%) patients with IBS and 13/73 (17.8\%) with CNSD. Fecal fat excretion was lower in patients with IBS as compared to pa-

Table 2. Report of D-xylose, Fecal Fat and Duodenal Biopsy in Patients with IBS and CNSD

\begin{tabular}{|c|c|c|}
\hline & \multicolumn{2}{|c|}{$\begin{array}{l}\text { Patients who had all the three tests } \\
\text { (urine D-xylose, fecal fat/fecal sudan and } \\
\text { duodenal biopsy) }\end{array}$} \\
\hline & Normal & Abnormal \\
\hline $\operatorname{IBS}(\mathrm{n}=1)$ & 1 & 0 \\
\hline \multirow[t]{3}{*}{$\operatorname{CNSD}(\mathrm{n}=5)$} & 5 & 0 \\
\hline & \multicolumn{2}{|c|}{$\begin{array}{l}\text { Patients who had two tests done } \\
\text { (any two of urine } \mathrm{D} \text {-xylose, fecal fat/fecal } \\
\text { sudan and duodenal biopsy) }\end{array}$} \\
\hline & Normal & Abnormal \\
\hline $\operatorname{IBS}(\mathrm{n}=14)$ & 4 & $\begin{array}{l}0 \\
\text { (one test normal and one } \\
\text { abnormal } \mathrm{n}=10 \text { ) }\end{array}$ \\
\hline \multirow[t]{3}{*}{$\operatorname{CNSD}(\mathrm{n}=28)$} & 9 & $\begin{array}{l}\text { (one test normal and } \\
\text { one abnormal } \mathrm{n}=19 \text { ) }\end{array}$ \\
\hline & $\begin{array}{r}\text { Patients w } \\
\text { (any one of urin } \\
\text { and }\end{array}$ & $\begin{array}{l}\text { only one test done } \\
\text { lose, fecal fat/fecal sudan } \\
\text { enal biopsy) }\end{array}$ \\
\hline & Normal & Abnormal \\
\hline IBS $(\mathrm{n}=18)$ & 7 & 11 \\
\hline CNSD $(\mathrm{n}=7)$ & 5 & 2 \\
\hline
\end{tabular}

IBS, Irritable bowel syndrome; CNSD, chronic non-specific diarrhea. In 96/129 and 25/73 patients with IBS and CNSD, no test was done.

The patients with IBS and CNSD having no test done were diagnosed only on the basis of symptoms (no history of blood in stool, no weight loss, no alarm symptoms). tients with CNSD (median $8.24 \mathrm{~g}$, range 5.3-15.1 g vs. $4.97 \mathrm{~g}$, range 2.6-25.1 g, $\mathrm{p}=0.008)$. Fecal fat (Sudan stain) was done in $22 / 129(17.1 \%)$ patients with IBS and 26/73 (35.6\%) with CNSD. Fecal fat excretion (droplets/hpf) was comparable in patients with IBS and CNSD (median 14 droplets/hpf, range 6-20 droplets/hpf vs. 12, range 6-25 droplets/hpf, $\mathrm{p}=0.29$ ).

\section{Results of histopathological examination of duodenal biopsy}

The histological evaluation of duodenal biopsy was done in 26/73 patients with CNSD; of them, normal villous patterns was seen in $21(80.8 \%)$, increased intraepithelial lymphocytes in 4 $(15.4 \%)$ and giardiasis in $1(3.8 \%)$. None had villous atrophy. No patient with IBS underwent histological examination of duodenal biopsy as this is an invasive test.

\section{Result of glucose hydrogen breath test}

Patients with CNSD more often had SIBO diagnosed by GHBT compared to patients with IBS and HC [16/73 (21.9\%) vs. $11 / 129(8.5 \%)$ vs. $1 / 51(2 \%)$, respectively; $p=0.001]$ (Table 1). The frequency of SIBO was higher in patients with CNSD than HC ( $p=0.003)$ but was comparable between patients with IBS and $\mathrm{HC}(\mathrm{p}=0.18)$. Also, the frequency of SIBO was higher in patients with CNSD than patients with IBS $(\mathrm{p}=0.007)$.

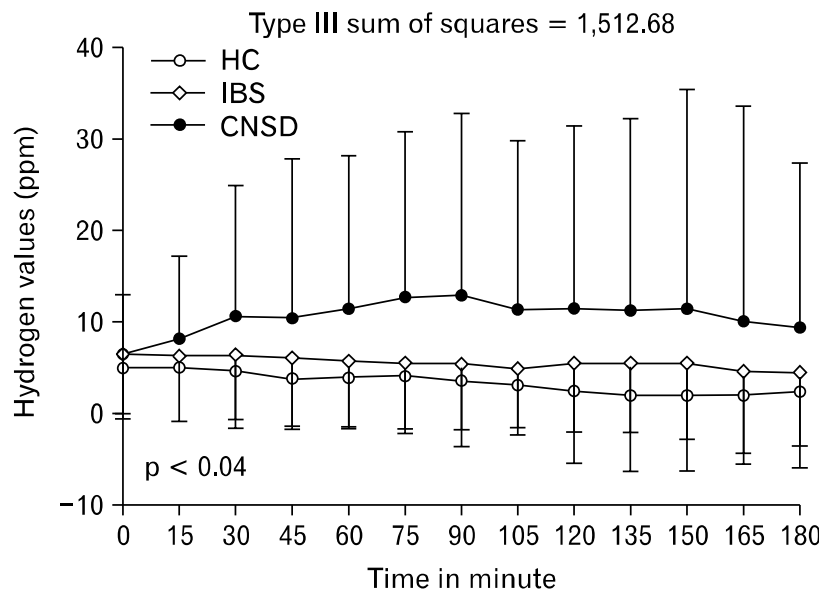

Figure 1. The time by group interaction showing the correlation of hydrogen excretion at different time interval on GHBT in patients with IBS, CNSD, and HC. The data was analyzed using repeated measures ANOVA using general linear model for the time by group interaction in both the analysis. IBS, irritable bowel syndrome; CNSD, chronic non-specific diarrhea; HC, healthy control. 
$11 / 122(9.9 \%)$ of I-IBS, and none (0\%) of C-IBS had SIBO $(\mathrm{p}=\mathrm{ns})$. The difference in frequency of SIBO in patients with D-IBS and other patients with CNSD was not significant [2/20 $(10 \%)$ vs. $16 / 53(30.2 \%) \mathrm{p}=0.13]$. The maximum hydrogen excretion was higher in patients with CNSD as compared to patients with IBS and HC (mean 19.3 ppm \pm 27.9 ppm vs. 10.9 \pm 15 ppm vs. $8.5 \pm 9.6 \mathrm{ppm}, \mathrm{p}=0.003$, Sum of square $=$ $8,333.8)$, respectively. There was significant correlation for time by group interaction for hydrogen excretion at different time within the groups, $p=0.04$, type III sum of square $=1512.68$ (Fig. 1). The maximum hydrogen excretion in patients with D-IBS, C-IBS and I-IBS was comparable (mean $8.3 \pm 7.9 \mathrm{ppm}$ vs. $9.1 \pm 8.8$ vs. $11.1 \pm 15.3 \mathrm{ppm}, \mathrm{p}=0.71)$.

\section{Discussion}

The present study showed that SIBO was more common in patients with CNSD (21.9\%) than those with IBS (8.5\%) and HC (2\%). 9.9\% patients with I-IBS and none of C-IBS had SIBO. Also, patients with CNSD had more breath hydrogen excretion following glucose ingestion than IBS and HC.

Previous studies reported contradictory results on the prevalence of SIBO in patients with IBS. ${ }^{14,32-36}$ The difference in the geographical origin of the studied population, criteria for diagnosis of IBS, methods for diagnosis of SIBO and methods of breath tests (substrate, instrument, gases analyzed, and diagnostic criteria) might explain the variation in prevalence of SIBO in different studies. In the present study, we have used Manning's criteria for diagnosis of IBS instead of more recent Rome criteria. Rome criteria has limitations for diagnosis of IBS in Asia, ${ }^{2,37}$ particularly in India as almost one-third of patients with IBS did not report pain or discomfort in a large study in India. ${ }^{29}$ Other studies from India supported similar finding. ${ }^{38}$ Pain and discomfort are essential for diagnosis of IBS according to Rome criteria. Classification of IBS into D-IBS and C-IBS also posed difficulty using Rome criteria as stool frequency was an important factor in classifying IBS using Rome I and II criteria. In fact, considering this, the recent Rome III criteria gave less importance to stool frequency. In many Asian studies, bloating, feeling of incomplete evacuation and meal-related symptoms were the common features of IBS $^{2,39}$ and stool frequency was comparable among patients who felt constipated or those who felt having diarrhea. ${ }^{29}$ In fact, for this reason, in a large study from India, $57 \%$ were I-IBS. ${ }^{29}$ Similar experience has also been reported from some other Asian countries. ${ }^{2}$
Higher frequency of SIBO in patients with CNSD is not entirely unexpected. Almost half of patients with MAS have been shown to have SIBO, ${ }^{13}$ which might be related to small intestinal stasis in association with large quantity of nutrient-rich fluid in the lumen. In fact, there could be etiologic and pathophysiologic overlap between MAS and D-IBS as evidenced by the fact that patients with PI-IBS, who have organic basis more frequently, are more often diarrhea-predominant like post-infective malabsorption syndrome, ${ }^{15,16}$ and have abnormal small intestinal permeability, ${ }^{17}$ Also, patients with D-IBS may have $\mathrm{SIBO}^{18}$ and lactose malabsorption ${ }^{18}$ more frequently. These findings may suggest that patients with chronic diarrhea, even if non-specific and D-IBS should be investigated for SIBO. Since our study was retrospective, need to investigate for malabsorption such as D-xylose test, fecal fat estimation and duodenal biopsy was decided by the clinicians; hence, every patient did not get all these tests done. Even if we have misclassified some patients with mild malabsorption into CNSD, our results are of importance in clinical practice. Secondary SIBO is common in patients with MAS due to various causes. ${ }^{40}$ If SIBO is found in patients with chronic diarrhea, specific treatment with antibiotics may benefit them.

Table 3. Demographic, Clinical and Laboratory Parameters of the Patients with and without Small Intestinal Bacterial Overgrowth

\begin{tabular}{|c|c|c|c|}
\hline & $\begin{array}{l}\text { No SIBO } \\
(\mathrm{n}=173)\end{array}$ & $\begin{array}{l}\text { SIBO present } \\
\quad(\mathrm{n}=29)\end{array}$ & p-value \\
\hline Age (yr) & $35(17-75)$ & $49(22-84)$ & $<0.001$ \\
\hline Sex (Male) & $131(76.0 \%)$ & $16(55.1 \%)$ & 0.144 \\
\hline $\begin{array}{l}\text { Chronic diarrhea } \\
\text { with negative tests } \\
\text { for MAS }(n=53)\end{array}$ & $37(21.4 \%)$ & $16(55.2 \%)$ & 0.0006 \\
\hline C-IBS $(\mathrm{n}=7)$ & $7(4.0 \%)$ & $0(0 \%)$ & 0.59 \\
\hline D-IBS $(\mathrm{n}=19)$ & $18(10.4 \%)$ & $2(6.9 \%)$ & 0.47 \\
\hline I-IBS $(\mathrm{n}=122)$ & $111(64.2 \%)$ & $11(40.0 \%)$ & 0.02 \\
\hline $\begin{array}{l}\text { Basal breath } \\
\text { hydrogen (ppm) }\end{array}$ & $5(0-21)$ & $6(0-18)$ & 0.396 \\
\hline $\begin{array}{l}\text { Maximum breath } \\
\text { hydrogen (ppm) }\end{array}$ & $7(0-31)$ & $28(10-156)$ & $<0.001$ \\
\hline $\begin{array}{l}\text { Urinary excretion of } \\
\text { D-xylose }(\mathrm{g} / 5 \mathrm{~g} / 5 \mathrm{hr})\end{array}$ & $1.17(0.2-1.96)$ & $0.94(0.26-2.4)$ & 0.748 \\
\hline Fecal fat (g/24 hr) & $6.5(2.6-25)$ & $4.7(3.9-12.9)$ & 0.438 \\
\hline Hemoglobin (g/dL) & $13.5(7-18.8)$ & $12.4(7.2-14.9)$ & 0.006 \\
\hline
\end{tabular}

MAS, malabsorption syndrome; IBS, Irritable bowel syndrome; C, D, and I indicate constipation predominant, diarrhea predominant, and indeterminate subtypes of IBS.

All the continuous data are presented as median and range. Values within parenthesis indicate percentages. 
Since older patients had SIBO more commonly (Table 3), we suggest that patients older than $40 \mathrm{yr}$ should be investigated for SIBO. Though hemoglobin was lower in patients with SIBO (Table 3), this might not be of clinical significance as most of the patients with SIBO had hemoglobin values within the normal range.

Patients with CNSD produced more hydrogen following glucose ingestion than the patients with I-IBS, D-IBS, and HC. Gastrointestinal symptoms like bloating, flatulence and pain, which are common in patients with IBS and CNSD, can result from excess gas production from bacterial fermentation of undigested carbohydrates. ${ }^{41}$ Patients with SIBO produce excess gases (i.e. hydrogen); moreover, gas distribution in the gut is abnormal in them with accumulation in small rather than in large intestine. $^{33}$ Development of symptoms following production of gas during hydrogen breath test in patient with IBS but not among $\mathrm{HC}$ has been documented during lactose hydrogen breath test. ${ }^{24}$ Gas accumulation in the small intestine may lead to symptom development due to its limited capacity to distend in contrast to colon, which can accommodate large amount of gas without discomfort. ${ }^{33}$ One of $51 \mathrm{HC}$ in the current study had SIBO. None of them reported any gastrointestinal symptoms indicative of IBS or other functional bowel disorders. This data is in accordance with those reported previously showing SIBO in $1 \%$ of $\mathrm{HC}$ using GHBT. $^{36}$

In conclusion, the present study showed that CNSD including D-IBS had higher frequency of SIBO than I-IBS and C-IBS. Therefore, clinicians treating patients with CNSD including D-IBS should consider testing for SIBO in them.

\section{Acknowledgements}

Authors thank Mr. Raghunath of Gastrointestinal Pathophysiology and Motility Lab of SGPGI, Lucknow for technical help.

\section{References}

1. Zaman A. Irritable bowel syndrome. Clin Cornerstone 2002;4:22-33.

2. Gwee KA, Lu CL, Ghoshal UC. Epidemiology of irritable bowel syndrome in Asia: something old, something new, something borrowed. J Gastroenterol Hepatol 2009;24:1601-1607.

3. Thompson WG. Irritable bowel syndrome: pathogenesis and management. Lancet 1993;341:1569-1572.

4. Talley NJ, Owen BK, Boyce P, Paterson K. Psychological treatments for irritable bowel syndrome: a critique of controlled treatment trials. Am J Gastroenterol 1996;91:277-283.
5. Schmidt T, Pfeiffer A, Kaess H. Abnormal intestinal motility in irritable bowel syndrome. Gastroenterology 1996;111:1400-1401.

6. Posserud I, Agerforz P, Ekman R, Bjornsson ES, Abrahamsson H, Simren M. Altered visceral perceptual and neuroendocrine response in patients with irritable bowel syndrome during mental stress. Gut 2004;53:1102-1108.

7. Wang L, Fang X, Pan G. Intestinal infection and irritable bowel syndrome. Zhonghua Nei Ke Za Zhi 2002;41:90-93.

8. Ghoshal UC, Park HJ, Gwee KA. Bugs and irritable bowel syndrome: The good, the bad and the ugly. J Gastroenterol Hepatol 2010 (In press)

9. Kim HS, Kim MS, Ji SW, Park H. The development of irritable bowel syndrome after shigella infection: 3 year follow-up study. Korean J Gastroenterol 2006;47:300-305.

10. Rubio-Tapia A, Barton SH, Rosenblatt JE, Murray JA. Prevalence of small intestine bacterial overgrowth diagnosed by quantitative culture of intestinal aspirate in celiac disease. J Clin Gastroenterol 2009;43:157-161.

11. Riordan SM, McIver CJ, Duncombe VM, Thomas MC, Nagree A, Bolin TD. Small intestinal bacterial overgrowth and the irritable bowel syndrome. Am J Gastroenterol 2001;96:2506-2508.

12. Ghoshal UC, Ghoshal U. Gut flora in health and small intestinal bacterial overgrowth syndrome. Trop Gastroenterol 2007;28:43-44.

13. Ghoshal U, Ghoshal UC, Ranjan P, Naik SR, Ayyagari A. Spectrum and antibiotic sensitivity of bacteria contaminating the upper gut in patients with malabsorption syndrome from the tropics. BMC Gastroenterol 2003;3:9-15.

14. Majewski M, McCallum RW. Results of small intestinal bacterial overgrowth testing in irritable bowel syndrome patients: clinical profiles and effects of antibiotic trial. Adv Med Sci 2007;52:139-142.

15. Thabane M, Kottachchi DT, Marshall JK. Systematic review and meta-analysis: The incidence and prognosis of post-infectious irritable bowel syndrome. Aliment Pharmacol Ther 2007;26:535-544.

16. Lee JS, Jung SA, Kim SE, Shim KN, Kim DY, Yoo K. The frequency of post-infectious irritable bowel syndrome (PI-IBS) in patients with acute diarrhea and a comparison with colonoscopic findings. Korean J Neurogastroenterol Motil 2004;10:43-48.

17. Gomez-Escudero O, Schmulson-Wasserman MJ, Valdovinos-Diaz MA. Post-infectious irritable bowel syndrome. A review based on current evidence. Rev Gastroenterol Mex 2003;68:55-61.

18. Rana SV, Mandal AK, Kochhar R, Katyal R, Singh K. Lactose intolerance in different types of irritable bowel syndrome in north Indians. Trop Gastroenterol 2001;22:202-204.

19. Remes-Troche J, Bernal-Reyes R, Valladares-Lepine M, AlonsoLarraga O, Gomez-Escudero O, Melendez-Mena D. Gastroenterology diagnosis and treatment guidelines of Irritable Bowel Syndrome; clinical features and diagnostic criteria. Rev Gastroenterol Mex 2009;74:58-62.

20. Zwolinska-Wcislo M, Galicka-Latala D, Rozpondek P, RudnickaSosin L, Mach T. Frequency of celiac disease and irritable bowel syndrome coexistance and its influence on the disease course. Przegl Lek 2009;66:126-129.

21. Wahnschaffe U, Ullrich R, Riecken EO, Schulzke JD. Celiac disease-like abnormalities in a subgroup of patients with irritable bowel syndrome. Gastroenterology 2001;121:1329-1338.

22. Caldarella MP, Balatsinou C, Milano A, Laterza F, Neri M. There 
is a relationship between celiac disease and patients with symptoms of irritable bowel syndrome. Gastroenterology 2002;123:1408-1409.

23. Wang J, Bei L, Pan G. Lactulose hydrogen breath test in small intestinal bacterial overgrowth. Zhonghua $\mathrm{Nei}$ Ke Za Zhi 1995;34:381-384.

24. Gupta D, Ghoshal UC, Misra A, Choudhuri G, Singh K. Lactose intolerance in patients with irritable bowel syndrome from northern India: a case-control study. J Gastroenterol Hepatol 2007;22: 2261-2265.

25. Ghoshal UC, Ghoshal U, Das K, Misra A. Utility of hydrogen breath tests in diagnosis of small intestinal bacterial overgrowth in malabsorption syndrome and its relationship with oro-cecal transit time. Indian J Gastroenterol 2006;25:6-10.

26. Abu-Shanab A, Quigley EM. Diagnosis of small intestinal bacterial overgrowth: the challenges persist! Expert Rev Gastroenterol Hepatol 2009;3:77-87.

27. Rao KP, Gupta S, Jain AK, Agrawal AK, Gupta JP. Evaluation of Manning's criteria in the diagnosis of irritable bowel syndrome. J Assoc Physicians India 1993;41:357-358.

28. Dogan UB, Unal S. Kruis scoring system and Manning's criteria in diagnosis of irritable bowel syndrome: is it better to use combined? Acta Gastroenterol Belg 1996;59:225-228.

29. Ghoshal UC, Abraham P, Bhatt C, et al. Epidemiological and clinical profile of irritable bowel syndrome in India: report of the Indian Society of Gastroenterology Task Force. Indian J Gastroenterol 2008;27:22-28.

30. Bala L, Nagana Gowda GA, Ghoshal UC, Misra A, Bhandari M, Khetrapal CL. 1H NMR spectroscopic method for diagnosis of malabsorption syndrome: a pilot study. NMR Biomed 2004;17:69-75.

31. Raffensperger EC, D'Agostino F, Manfredo H, Ramirez M, Brooks FP, O'Neill F. Fecal fat excretion. An analysis of four years' experience. Arch Intern Med 1967;119:573-576.

32. Pimentel M. The prevalence of small intestinal bacterial overgrowth in irritable bowel syndrome: IBS vs. healthy controls (not historical definitions). Gut 2008;57:1334-1335.

33. Lupascu A, Gabrielli M, Lauritano EC, et al. Hydrogen glucose breath test to detect small intestinal bacterial overgrowth: a prevalence case-control study in irritable bowel syndrome. Aliment Pharmacol Ther 2005;22:1157-1160.

34. Lin HC. Small intestinal bacterial overgrowth: a framework for understanding irritable bowel syndrome. JAMA 2004;292:852-858.

35. Vanner $\mathrm{S}$. The small intestinal bacterial overgrowth. Irritable bowel syndrome hypothesis: implications for treatment. Gut 2008;57: 1315-1321.

36. Rana SV, Sinha SK, Sikander A, Bhasin DK, Singh K. Study of small intestinal bacterial overgrowth in North Indian patients with irritable bowel syndrome: a case control study. Trop Gastroenterol 2008; 29:23-25.

37. Gwee KA. Defining IBS in India: a brave new world. Indian J Gastroenterol 2008;27:3-4.

38. Banerjee R, Choung OW, Gupta R, et al. Rome I criteria are more sensitive than Rome II for diagnosis of irritable bowel syndrome in Indian patients. Indian J Gastroenterol 2005;24:164-166.

39. Ji SW, Park HJ, Lee JI, Oh HY, Lee SI, Park IS. A comparison and validity of various diagnostic criteria of irritable bowel syndrome. Korean J Gastrointest Motil 2002;8:21-30.

40. Ghoshal UC, Ghoshal U, Misra A, Choudhuri G. Partially responsive celiac disease resulting from small intestinal bacterial overgrowth and lactose intolerance. BMC Gastroenterol 2004;4:10-16.

41. Madrid AM, Defilippi CC, Defilippi GC, Slimming AJ, Quera PR. Small intestinal bacterial overgrowth in patients with functional gastrointestinal diseases. Rev Med Chil 2007;135:1245-1252. 